\title{
Conceptualizing Creativity and Strategy in the Work of Professional Songwriters
}

Paul Long and Simon Barber

\begin{abstract}
Drawing upon interviews conducted as part of the Sodajerker on Songwriting podcast this paper explores professional songwriting as musical labor. It explores how songwriters conceptualize creativity and what strategies they employ for the delivery of original songs. It argues that individuals evince a faith in their own autonomy in the face of the demands of form and industry, expressing intuitive concepts of inspiration and practical insights into the nature of their work as work. The paper suggests that achieving and maintaining success is affirmed in a conjunction of value that is both economic and aesthetic, personal and public.
\end{abstract}

\section{Keywords}

Songwriting, songwriters, songs, professionals, creativity, labor, work, strategy, routine, risk, reward, Sodajerker.

\section{Author information}

Paul Long, Birmingham Centre for Media and Cultural Research, Birmingham City University, The Parkside Building, Birmingham B4 7XG, UK. Email:

paul.long@bcu.ac.uk.

Simon Barber, Birmingham Centre for Media and Cultural Research, Birmingham City University, The Parkside Building, Birmingham B4 7XG, UK. Email: simon.barber@bcu.ac.uk.

\section{Corresponding author}

Simon Barber, Birmingham Centre for Media and Cultural Research, Birmingham City University, The Parkside Building, Birmingham B4 7XG, UK. Email: simon.barber@bcu.ac.uk. 


\section{Introduction}

This paper is prompted by a question about a fundamental aspect of the creative labor of musicians: what does it mean to write a song? While all musicians might be expected to be creative in some way, writing songs is not something all do or indeed are able to do. While not all musicians who write songs necessarily earn money, let alone make a living from this aspect of their creative activity, our concern here lies in understanding the place of the song in a value chain of production for those who do. We thus extend our query to ask: how do songs and songwriters emerge? Who writes songs and why? How do songs take the form that they do? In fact, what does a songwriter recognize as a song? In order to address these questions therefore, we explore accounts from professional songwriters regarding their conceptualization of creativity. In so doing, we focus on their strategies for its cultivation in the production of songs understood as a particular form of a musician's work. As we argue, a sense of song work is a means of overcoming the intrinsic uncertainties of the creativity of creative labor. It involves making assessments about the work one produces and indeed, one's own abilities and identity as a songwriter.

Songwriting is undoubtedly a part of the broader industrialized nature of popular music and songs are organized and oriented to its commercial injunction. It is curious therefore that what is a foundational aspect of the economy of the music industries and of the labor of professional musicians has received only partial attention in terms of the work it involves. We discuss this issue with reference to extant studies of songwriting below but a representative example of the limitations we have in mind is apparent in Peter Tschmuk's Creativity and Innovation in the Music Industry. Aiming to understand ways in which novelty is created, Tschmuk delineates "a network in which the production and distribution of music occurs in a process relying on the division of labor and the help of the latest technologies" (2). While songs and songwriters do appear in this account, the kinds of fundamental questions of why and how songwriting occurs are not considered which is a notable oversight considering its role as a fount of new work. In fact, songwriters and their work often appear to exist without reference to the particularity of the origins, conventions and manner of their practice, whether at organized sites of production such as Tin Pan Alley or labels like Stax or Motown, or in their role as writer-performers alone or in bands.

For us, Tschmuk's study demonstrates an abiding issue for popular music studies. Attention to the status of songs qua songs is often overlooked in favor of, or conflation with, the central role of the recording and its mediation in defining popular music culture. Of course, not all musical recordings are of songs per se, nor are all recording artists songwriters, and not all professional songwriters - those who make a living from this work - are recording or performing artists. However, a song is not reducible to a recording, although many songs are indeed formulated in the studio as part of that process. Furthermore, a song is a form that might be created and have an existence outside of a recording, via the longstanding practice of publishing for instance. A song might also have an existence beyond the circuit of exploitation of the value chain of music. Here, pre-industrial (and pre-music industry) folk songs come to mind as well as the fact that not all songs are recorded or indeed get to be heard by audiences, whether created by professional recording artists or amateurs. That said, even the home-producer who might write for reasons of personal satisfaction is likely to reference the economic determinants of the music industries inasmuch as they impact upon aesthetic conventions. 
In proceeding, we first discuss issues arising from the extant work on songwriting relative to the growing body of work on cultural labor. We then outline how our empirical insights are drawn from a sample of accounts collected in a series of interviews for Sodajerker on Songwriting, a podcast devoted to the art and craft of songwriters. Our analysis explores how individuals come to pursue this role in the absence of any organized routes to the profession. We then turn to consider how songwriters articulate the nature of their work and creative status. We argue that in the creation of songs, songwriters also produce ideas about what songs and songwriters are or are not. Such ideas aid in motivating and supporting careers and help mitigate the intrinsic risk and uncertainty involved in this form of labor for what is in effect a range of freelance composers. With a faith in their own autonomy and sense of the demands of form and industry, individuals express intuitive concepts of inspiration and practical insights into the everyday nature of their work as work. They articulate the way in which organized approaches to pop songwriting facilitate creativity, productivity, and indeed the identity that confirms their ability and status. This research then, is a contribution towards understanding empirically the particularity of this area of the labor of musicians, of how achieving and maintaining success as a songwriter is affirmed in a conjunction of value that is both economic and aesthetic.

\section{Researching creativity, researching songwriting}

While this study is specifically about making music it can be understood in the context of wider research concerned with the general features and conditions of creative labor and "'Creativity' as an input (rather than culture as an output)" (Oakley and O'Connor 3). David Hesmondhalgh uses the term "symbol creator" to describe individuals at the core of creative production, "those who make up, interpret or rework stories, songs, images and so on" (6). While so much research has been concerned with the endpoint rather than the origin and process of creating symbolic goods, a growing body of work offers insights into the nature of what it is that creators actually do when they make up, interpret or rework (e.g. McRobbie; Caldwell; Mayer et al; Banks; Hesmondhalgh and Baker; Conor; Taylor and Littleton). This range of work surveys the scope of the so-called creative industries, between the fashion industry, media and fine arts, encompassing a variety of ways of thinking about production, and as Littleton et al. suggest "any attempt to investigate it must contend with the multiple definitions and associations of the creative" (1).

Clearly, the conditions, demands and conventions of songwriting are rather different to those of being a designer of haute couture, film director or sculptress. Even where palpable commonalities aid understanding and theorisation, to see such activities together might overlook the specificity and nuance of any one. Indeed, some aspects of creative production are in need of closer attention. Valuable here is Mike Jones' suggestion that while we might know much about our emotional relationship with popular music as consumers, conversely we know 'next to nothing about how such music is made' (148). Jones' further reflections on his personal experience as a songwriter serves to illuminate the lack of knowledge about this specific area of production. Nonetheless, it is important to recognize that there are those that do claim such knowledge who address a market eager for the secrets of success, sharing information about fundamental techniques of songwriting (e.g. Hirschhorn; Blume; Pattison; Coryat and Dobson). Such 'how to' books afford little space to theorising how the professional songwriter can be understood as a working musician, and focus 
instead on practical techniques for generating new musical and lyrical ideas as well as instructional material on music publishing and copyright.

The polar opposite of such guides perhaps are those of a genre devoted to interviews with established songwriters about their craft (Zollo, Egan and Rachel): 'how I did it' or 'how I do it', perhaps. This material is presented in the form of conversations with journalists and lacks systematic analysis of the sort that might establish commonalities and aid understanding of how these professionals conceptualize their creativity and understand their place within the wider context of the music industries. As Jones complains, such work is often in thrall to romantic and ineffable notions creativity, as a product of intuition, instinct or inspiration, and which "does not take us closer to the idea that songwriting might be a 'job' like any other" (223).

In addition to the practical guide and the interview are a number of popular texts which historicize songwriting as a component of the wider music production and distribution apparatus of the music industries. These are typically organized by specific historical and geographical scenes, labels or companies. For instance: Tin Pan Alley (Jasen); The Brill Building (Emerson); Motown (George); or production teams like The Chic Organisation (Easlea) and Stock, Aitken \& Waterman (Harding). Alongside Jones' contribution, extant academic explorations of songwriting, include musicological approaches to song forms and characteristics (Burns, Fitzgerald, Hass et al.), sociological studies of conflict and reward (DeLaat) and models of creativity and flow emerging from the field of psychology (McIntyre). Stephen B. Groce's work on socialization and the process of becoming a songwriter touches on questions raised in this paper, though it offers very little on how songwriters articulate or understand the act of writing songs.

Bennett's work needs acknowledgement here as he has asked similar questions about the understanding of songs and how their successful production informs professional status. Bennett is interested primarily in documenting the place of "negotiated creativity", captured in action in the collaborative process. This is employed in conjunction with a "stimulus processing' theory" to extrapolate models for writing and collaboration. He contends, for instance, that there are six non-linear and interacting processes at play during a typical co-writing session, and seven possible models for collaboration. This approach has the appearance of an evaluation of effective method and its application here is limited in relation to the aim of understanding the songwriting process as a form of work.

Mindful of the specificities of the work of musicians, we can turn again to how a wider literature has articulated the tensions of creative work and what is at stake for workers. Cultural expression offers autonomy and self-actualization (Holt and Lapenta) yet the experiences of workers are often presented in terms of selfexploitation, a blurring of the boundaries between work and leisure, and bulimic work patterns summarized in descriptions of the precariousness of employment patterns (e.g. Murray and Gollmitzer; Hracs and Leslie). Certainly, making one's living in the cultural industries is a perilous business in lots of ways, although as Pierre-Michel Menger points out, the very essence of the production of cultural goods is founded on risk. Individuals seeking to make up, interpret or rework in writing, painting or composition and so on embark each time on an uncertain course without a defined nor guaranteed endpoint (3). Whether we think of a piece of abstract art, novel, film or indeed a pop song, each act of creation seeks to produce something new. In each case, and allowing for the ways in which creative processes are inflected by rationalization or market research, conditioned by genre and standardized convention, their value and 
appeal cannot be wholly anticipated. As Menger notes, if there is a challenge created by uncertainty regarding goal, process and outcomes, "it is also a precondition for originality and invention, and for more long-range innovation. It is both necessary to the satisfaction taken in creating, and a trial to be endured"(Ibid).

Menger's insights are a useful challenge in turn for pondering the absence of knowledge of the satisfactions and trials of music production as identified by Jones. Here, it is helpful to acknowledge the objective and subjective relations of individuals betwixt and between their own sense of creative motivation and the structural determinants of the music industry. In this context, and as Menger further suggests, any analysis of creativity must account for enduring concepts of "the artist as radically desocialized, living and working outside of a community of peers" (Menger 114). Nonetheless, as Pang notes, artistic sensibilities are valuable to creative workers but they are also rational actors whose "instincts" and decisions are geared towards creativity that sells. As Bennett, Toynbee and Jones have all suggested, the musician is always caught between two worlds. In Jones' words, work "consists of consistently mediating, negotiating, and reconciling the shifting dimensions of 'art-making' and 'commerce-satisfying'." (234)

Romantic myths of the atomized worker then, can be deconstructed with reference to an economic value chain that inflects the artistic considerations of individuals but also the chain or web of values that define the conventions of each creative sector. Such conventions are articulated in the work of both Pierre Bourdieu and Howard S. Becker, both of whom, mutatis mutandis, outline how the context and particular conventions of "fields" and "art worlds" respectively, qualify production, the possibilities of innovation or indeed the nature of one's entry into such activities, and acquisition of a place and self-understanding as a creative worker (see Becker and Pessin). Likewise, psychologists of creativity like Robert Weisberg, Keith Sawyer or Mihaly Csikszentmihalyi have sought to explore the contextual, social nature of creativity. Csikszentmihalyi for instance has been "forced by facts" (103) to view individual creativity in terms of an operational environment which has culturalsymbolic and social aspects - the domain and field respectively. As such, he argues that creativity as process is something that can be understood at the interaction of these aspects, between individuals, domains, and fields. He writes that the domain is essential to creativity as "It is impossible to be a genius [...] in the absence of a symbolic system. Original thought does not exist in a vacuum. It must operate on a set of rules, of representations, of notations." (103) Whether the present research encompasses anyone who might be labeled genius is a subjective judgment but our concern is with individuals working within the domain of the music industries and the conventions and expectations of popular music culture. The dynamic relationship of individual and industry determines the nature of what counts as creativity and its successful realization in practice. As Jones suggests of his own experience: "In the demanding activity of constant re-adjustment to fresh perceptions of a dynamic constellation of mutating, commodification-driven considerations I remained an agent, certainly, but only in so far as I acted to produce what and how I determined required to be produced at any particular conjuncture. This does not mean that I had to write [...] but it does affect how I wrote" (234-6). How then might we gain a broader sense of the work of songwriters as a group?

\section{Talking about songwriting}


In Bennett's approach to capturing the creativity of songwriting, he performs statistical analysis on the characteristics of chart hits, carries out ethnographic work in the studio and participates also as a co-writer of songs. The methodological model for this research is Bridget Conor's study of screenwriting, which uses interviews in order to understand the implications derived from "how writers describe and experience the work, how craft and creativity are defined and experienced" (Conor 12). Research here is built upon the analysis of a series of semi-structured interviews conducted as part of the Sodajerker on Songwriting podcast, founded in late 2011 by the British songwriting duo Sodajerker: Brian O'Connor and one of the present authors, Simon Barber. ${ }^{1}$ At the time of writing there were 90 episodes of this program available, representing a significant achievement in which established songwriters discuss their approach to writing.

Sodajerker's interviews illuminate the working practices and ideas of a range of professional practitioners. These encompass Brill Building-era songwriters of the 1960s such as Barry Mann and Cynthia Weil and Neil Sedaka, to those who are the acme of contemporary modes of expression such as Alicia Keys, Scroobius Pip or John Grant. Interviewees have a couple of obvious guises: as performers and producers, e.g. Paul Simon, Marcus Miller, Joan Armatrading, Narada Michael Walden or Todd Rundgren; and as co-writers and collaborators recognized for their skill at writing songs for and with other artists. This second category includes people like Albert Hammond, Guy Chambers, Beth Nielsen Chapman, Eg White, Sacha Skarbek, Miranda Cooper and Dan Wilson and provides the focal point for this research.

While conceived as a form of entertainment rather than for the purposes of academic research, Sodajerker on Songwriting is useful here because of its attention to the questions set out in the introduction concerning what it means to be a songwriter. While the published episodes of Sodajerker's podcast are mediated through the editing of longeurs and diversions unnecessary to the format, we draw here upon transcripts of its original long-form structure.

Sodajerker is distinct from others in its expanding field such as Song Exploder. The latter is typical in echoing some of the problems identified in thinking about songs identified above. It is concerned with the inspiration and decisions made in the recording process, and the design and construction of recordings as sonic artefacts, rather pursuing insights into how the songwriter rationalizes what it means to be a songwriter. In Sodajerker on Songwriting we encounter an instance of songwriters talking between themselves, foregrounding an interest in their craft and creativity rather than "tales of the road", technologies or the economics of the business, although the latter is often an unavoidable issue. These interviews offer a sense of the individualized and industrial contexts of creativity and commissioning. What emerges, are insights into the generation of ideas, songwriting routines, the construction of melodies and lyrics, and strategies for co-writing and collaboration.

Each Sodajerker interview is the result of a process of biographical, historical and musical research, which is carried out in advance by the hosts of the podcast. A set of about 45 questions is prepared, which results in a discussion lasting around one hour. Although there is a pre-determined structure for the interview, this is understood to be flexible; digression is common and interviewees are encouraged through followup questions to expand upon interesting points and lead the conversation into unanticipated areas. Here, detailed diversions into the banal aspects of routine and process for interviewees often come into focus. The structure of the interview depends on whether the interviewee is currently in a promotional cycle. If this is the case, then 
recent material is dealt with first in order to emphasize the writer's artistic and commercial currency in the present day. Following this, questions will typically deal with the capture and development of ideas for songs, recognisable songs from the writer's back catalogue and any lesser known songs for which there are specific questions about the nature of their writing or production. Biographical questions, such as those pertaining to musical influences, family life, and early songs provide additional context to the interview with a drive towards current work and future goals before concluding.

Overall, what interviewees say is less interesting for any absolute truth claims than for how each manifests a set of narrative tropes about songwriting. These evince a view of what it means to be a musician in a shared space of practice and industry and a faith in one's individual expression as a particularly creative person. Each reach for normative references in speaking about songwriting, articulating what is often felt in bodily, or psychic terms, or held to be intuitive in origination and judgment. As Albert Hammond reflects on the composition of "The Air that I Breathe," "I just put my fingers on a guitar and it sounded good and I went, ah, great, you know, 'cause I never learnt music, so I do it by ear, you know, whatever feels good." Nonetheless, such statements have meaning and, as Keith Negus and Mike Pickering affirm in acknowledging these aspects of creative work, "it remains the case that the creative experience requires a will to expression, and to communication with others" (22).

On this note and in reflexive mode, it is worth remarking on the manner in which many songwriters are practiced in narrating their ideas, approach and experience. An ability to articulate as well as demonstrate one's ability and expertise is clearly an important aspect of one's professional repertoire. While the discourse of performing artists mapped by Sodajerker tends to focus more on their own personal "journey," or the self-actualization of their creative vision, professional writers often foreground how they communicate with other people about the creative core of their work in order to produce songs and to earn a living. Thus, in our approach to these sources we echo Taylor and Littleton's attention to the "discursive resources" of interviewees (42). Those whose analyses "go beyond treating talk as straightforward description or reportage", or limpid evidence of the moments described or of "the speaker's feelings and opinions." Rather, utterances are situated in the context of the arts world, or here in the conventions of music, and present a "versioning of collectively-held meanings and values [...] which are assumed to pre- exist any speaker's talk, and to influence what can be said" (42).

\section{Conceptualizing creativity: producing the songwriter}

It is no surprise perhaps that accounts of songwriting by Zollo and others reproduce romantic notions of songwriting founded on ineffable logics. For instance, one of the challenges of investigating creative work is the degree to which individuals are able to articulate the essence of what they do as work. In so doing they themselves often rely upon the familiar notions of creativity ex nihilo, describing particular songs as a "gift" whose origin need not be examined too closely, however fanciful or lyrically its explanation (Kimpel). Albert Hammond for instance states that "Sometimes I don't feel I write the song, I just feel I'm an object here that energies from out there come through me, so I can put them down and have the world hear it." Likewise, Jimmy Webb elegantly reveals that inspiration comes so easily on occasion that it's as if "a wind blew through the room and left a song on the piano." In the same vein, songwriters also claim to have dreamed songs, echoing Paul McCartney's famous 
account of waking with "Yesterday" fully formed (Turner 92). Dan Wilson says something similar about the creation of "Secret Smile" when he awoke with the song in his head and simply wrote it down: "I was totally convinced that it was a preexisting song that I had stolen or remembered from somebody else."

Such motifs inform powerful structuring stories for both creative workers and consumers and have a normative role in explaining distinctions between writers in terms of concepts of talent and the hierarchies it enables. Such frameworks have value in underlining the identity of the songwriter and the value of their oeuvre although in the end in each account is offered a balance between myth and pragmatism, deploying both economic and psychological explanations for their work. Each expresses awareness of their autonomy and individuality but in the context of the determinants of the industry and cultural system of songs themselves. In explaining the necessary strategies and routines for conceptualizing what a song is, interviewees like Wilson thus offer frameworks for understanding why their creators might occasionally dream them into existence or feel attuned to a spiritual force that presents songs as if fully formed. Yet it is ultimately an acquaintance with work that undermines any sense of the ineffable and the idea that contingency might determine success as a songwriter even if uncertainty is a structural feature of the creative process.

Menger suggests that the uncertainty of creative labor is not "exterior" (4) to it, meaning that the aesthetic or commodity value of any output is not wholly dependent on the confirmation of audience and market. Uncertainty does not mean that an artistic career can be compared to a lottery in which anyone might have a go: "trusting it to chance, since the ingredients of original invention cannot be specified $a$ priori. This schema would lead everyone to overestimate his chances of success by underestimating the power of selective comparisons" (4). Success in creative work is dependent upon evaluation by peers and audiences the environment in which it takes place, the quality of labor and above all the particular nature of the creative individual. As Csikszentmihalyi suggests, it is not sufficient to be able to access a domain like popular music in order to offer creative input, individuals must have "the ability and inclination to introduce novelty in the domain" (117).

How then does one acquire ability and how does one come to understand one's inclination? The prodigious array of "how to" books available as well as accredited educational qualifications, and even participatory workshops offered by professionals like Sodajerker interviewees Beth Nielsen Chapman or Chris Difford suggest accessible ways into the domain of songwriting. Nonetheless, there is no formalized route to songwriting or guarantee of work. We suggest therefore that the status of the songwriter is achieved largely as a result of a form of individual cultural entrepreneurialism in which the creative makes their own identity, expertise and reputation with each song they write and make available.

In the self-narration of songwriters, individuals variously reflect on the discovery of their vocation, how they developed their skills and found their way to the music industries. Wilson, for instance, states: "I think I figured out that I was going to write songs and be a singer when I was 11." How one might envisage the realization of such ambition is another matter, and few are so single-minded. As Miranda Cooper of Xenomania claims: "It didn't enter my head that you could even be a pop star or that you could be a songwriter." Yet that is how she has established herself and whatever the discourse of "natural talent", songwriters are made not born. To be equipped to write a song convincingly involves a trajectory of the acquisition of knowledge beyond simply acquainting oneself with existing work and conventions as a listener. This knowledge informs the skills, confidence and indeed the formation of 
what Jason Toynbee calls a "space of possibilities" (38) and indeed, the expectation that one might be a songwriter. This space suggests that not only is creation feasible but so is remuneration, so inflecting the nature of any aesthetic inclination and commitment of resources.

In their interviews with artists, Taylor and Littleton observe how "creativity and creative work are presented as being a feature of speakers' early experience, with a creative environment being characterized as involving some shared engagement in creative work or encouragement to pursue it" (50). Unsurprisingly, Sodajerker's interviewees similarly identify formative creative encounters as causal and explanatory in their own narrative in terms of a "logic of success" (Taylor et al. 82). Some evince aspects of the autodidact: Albert Hammond learned songs from records discarded from jukeboxes, his barber teaching him guitar chords as a means of understanding the nature of songs. Others reflect on familial milieu, in which music consumption and education were environmental and structural features. Guy Chambers grew up with a father who was flute player in the London Philharmonic Orchestra and a mother who worked for Decca "so there was always a lot of music in the house and a lot of records [...] and I was taken to concerts from quite an early age." This does not suggest any simple template of disposition and ability that imprints itself on an individual. Eg White for instance identifies his formation as part of "a classical music family," in which pop "just didn't exist." While his parents and siblings were skilled in particular instruments, he was merely "adequate" at a range of them. He notes however "Those skills are rubbish in classical and great in pop."

Several songwriters explain how they found their way to this role as a result of disappointments as performers. Discovering that they would never be center stage is a factor in confirming their evaluation of options in a field that offers prospects for selfactualization. Some found themselves working in contexts where the music they were making did not measure up to their personal aspirations. White was a part of the band Brother Beyond, making records with some success: "then one day I woke up and thought, 'no this isn't so good, this isn't what I want to do." Sacha Skarbek recalls how "The band that I was in was okay but it wasn't great. We got a publishing deal with EMI but we never really were going to take off, but I sort of realized I could, you know, improve some of the connections I made there." Chambers began as a keyboard player and arranger working for Julian Cope, The Waterboys and World Party. His attempts to share his own songs in each context suggested that they did not quite fit with these contexts and his efforts were disparaged.

In a more self-critical vein Cooper reflects that as a performer "I was definitely out of my depth." It was during her unsuccessful time in a band that she was able to explore what it meant to be a writer. She was encouraged by Xenomania founder Brian Higgins, authorized to make a contribution to one song and discovered that "It was really fun and I really enjoyed the process." She made a decision not to continue as a performer, turning down the chance to capitalize on a potential hit, tours and so on, in favor of something that appeared creatively rewarding by comparison: "Suddenly it felt like this was something much more meaningful." For Cooper, success as a writer came slowly. It took several years to produce a hit and she benefitted from the patronage of Higgins, learning how to be creative and nurturing this quality through persistent application and hard work, spending "months just writing, writing, writing, writing, writing, getting ready, gearing up for something."

\section{Making creativity happen: producing the song}


Cooper's developmental experience confirms Sondre Lerche's insight that: "You have to make room for the work. You can't just sit around and wait for magic to happen." As songs don't always arrive on a breeze or come completely formed from dreams, how then are they formulated and what strategies do songwriters employ to make them happen? A starting point, as Hesmondhalgh and Baker note, is to recognize that approaches to creative work as work affirm Raymond Williams's assertion that "Culture is Ordinary" (18). Ordinariness is characteristic not only of "a whole way of life," or the place of symbolic products in our lives, but in the nature of where and how culture is created. This quality is adumbrated in songwriters' discourse, underlining one way in which theorists of creative labor have described how boundaries of work and not work are blurred. In looking for material and inspiration for instance, Allen Toussaint advises of a need to be inspired by one's environment "You might have seen two people on the corner kiss quickly. There you are. They kissed on the corner. You don't want to miss that." Similarly, individuals like Wilson feel a need to be attuned to inspiration at all times, as "everything is fodder." Ideas and prompts come out of the blue in the everyday and so one has to be both receptive and dedicated to ideas even if there is a personal cost:

Those periods of time are weird for me to be married and have a family because it's like I'll be with one of my daughters but they're only a thin overlay on my eyes. Everything behind that is music. I feel bad about it because I love them but it's a state you get into. It's like a trance that can be much of the day (Wilson).

Menger (3) suggests that art is a paradigmatic activity that is not very routine, yet many of the songwriters discussed here demonstrate that routine is exactly how they offset risk to generate results. Beth Nielsen Chapman has an elaborated conceptual framework for describing creativity and the specificity of her approach to songwriting. She conceives creativity as a resource, a raw material available to all, yet something that is not equitably apparent or accessed. She suggests that in order to nurture this resource, songwriting involves organisation and labor, setting out discrete blocks of time in which whimsical attitudes to one's muse and art need to be put aside in the face of practical pressures such as getting one's children to school and paying the bills. She describes her creativity as akin to staying in shape by going to the gym. For her, spending time at work on songwriting aims to nurture inspiration through applied activity so that the next day, apparently unbidden, something might come up in another context. She thus allows for "unknown" qualities - that could be called innovations - which are engaged through use of "the muscle of not knowing what you are doing." In spite of setting out rules, she accepts a possibility of "writing from the ether," the intrusion of unconsciousness allowing for surprise and rule breaking to intrude, although it is the routine that maintains her "muscle of creativity" to this end.

Wilson regularly follows a regime in which "I do a song a day process every three years and I usually do it for 30 days and quite often it extends further." In one such instance, he wrote "an avalanche of songs" from which emerged the popular "Your Brighter Days". His applied work ethic sometime conflicts with other, more laissez-faire approaches. As he recalls of one collaborative songwriting session, his co-writer complained that he was feeling uninspired and so sought to end the day's work. As he complains 'I'd be like, 'What the fuck? Wait a minute! You're not feeling it? You've got this ridiculous job of goofing around for a living and you're not feeling it? What are you going to do instead? Go to the beach?"' This report allows 
for other versions of a work ethic, and of course, one image of the glamorous reward of such labor would be exactly to go to the beach but for Wilson such diversions are unthinkable.

This last anecdote offers insight into a situation in which risk, routine and creativity come into sharp focus. As we have argued elsewhere (Long and Barber), songwriting can be thought of as a particular form of emotional labor for the manner in which it deploys affective authenticity, a quality which is drawn upon as a song is performed and consumed. Arlie Hochschild identified work in which flight attendants, for instance, were required to display emotions and feelings as part of their labor. As she writes: "emotional labor is sold for a wage and therefore has exchangevalue [...] This labor requires one to induce or suppress feeling in order to sustain the outward countenance that produces the proper state of mind in others" (7). This affective dimension in part explains the reliance upon normative expressions about one's feelings and intuition - and the need to 'feel it' in Wilson's collaborator. In accounts of collaboration aimed at generating creative outputs we gain a particular sense of the emotional labor and routines of songwriters. Figures like Wilson, Skarbek, Cooper, White and others are regularly enlisted for co-writing sessions. In such instances, they are paired with high profile performers and other successful writers for focussed periods in which they are expected to deliver meaningful outputs.

Here, Eg White's account of collaboration is particularly useful for understanding Hochschild's conceptualisation, which involves recognition of "feeling rules" and how creativity is nurtured as a result of experience and routine (7). White describes situations in which he is paired with individuals he has never met and so "We'll probably talk for an hour, I'll try and work out what they like, why they like it, whether they're resonating to something for musical reasons or emotional reasons." He describes imagining work in terms of its potential "shape", examining styles and themes that characterize the collaborator's identity in order to align ideas with it. In such situations, the kind of attributes professional songwriters require in order to generate results include persistence - "just waiting for luck to be with you" - and flexibility. In such circumstances, White is attuned to how his own ideas sometimes outrun the comprehension, ego and abilities of his collaborator. As a result, his ability to understand and conceptualize songs as creator and consumer comes into effect. Sometimes abnegating any priority for his own ideas, he offers a reflective approach to the creations of others in which his role is either as producer or editor in assessing the integrity of the work: "I'm practically just there saying, 'Well I don't believe it."

The stresses, strains and risks - to self, to writing partner and to the production and integrity of the creative work itself - are apparent in contexts of collaboration where interested parties attend in expectation. Skarbek considers that being in a room with other writers in which everyone is making a contribution is productive, yet problems arise from "outside". For instance, "When a manager starts saying, "oh no, I think that bridge isn't right." Creative integrity is something to be maintained by keeping the encroachments of commerce at bay. Nielsen Chapman echoes this principle remarking that, while business matters, creativity needs prioritizing and protecting. Likewise, routine needs managing in order to ensure that it does not produce banal templates for songs. She relates how her first hit "Strong Enough to Bend" elicited a range of calls from publishers and producers asking for more from the same "stamp" which caused a creative blockage for her. To her thinking, she did not know how to "do it" in the first instance, and so the idea that one could simply reproduce success by reducing one's output to formulae was to be resisted. As Eg White suggests, after outlining his rationalized way of working: "I say all of this, but 
in fact when I look at this formula I realize probably most of the tunes that have done really well weren't written according to this. They're just some blind panic really."

The adoption of routine might be practical but it is rather unromantic as its ultimate goal is to deliver tradable goods as much as it affirms individual artistry. Songwriter discourse is instructive here for how it manages the trade-off between these aspects of success, and for how individuals describe forging space in which to work beyond the determinants of commercial imperatives in order to maintain a sense of creative integrity. White is reflexive about the prioritising of creativity for itself even if it has no commercial appeal. In such circumstances, in collaborating or trying to make a living with one's solo compositions, "The right thing to do is try to make the best possible music you can and hope that the marketplace is a broad church and not worry too much." Chambers relates the importance of projects that are "just for fun" that may ultimately offer invigoration of one's skills and appeal. In such instances "You might learn more from those projects than the ones where you're just trying to write a hit song, which is a whole different way of thinking and working."

For some, ideas and practices of routinization of creative work do present dissatisfactions, emphasizing the ethos of those in Wilson's account of collaborators who were unable to "feel it" on demand. As Albert Hammond suggests, "I can't write songs mechanically, you know, I can't go nine to five every day and go, 'I'm going to write two songs a day or a song a day.' I write when I feel it." Such is the power of the idea of ex nihilo inspiration that it can cause a reflexive suspicion of one's own professionalism and routines that are designed to counter the risk that it might not be available. Todd Rundgren recalls having organized his processes so efficiently at a moment marked by his hit "I Saw the Light" that he suspected himself of working to a formula. He reflects "it got to the point that I could finish a song in twenty minutes, I started to think 'maybe I'm not taking this seriously enough?"'

The routinization and application to creativity outlined thus far raises questions about the nature of the output that emerges from this process and how a core skill of the songwriter is expressed in assessing the quality of ideas for songs. Songwriters always have an array of elements of songs "in development," some of these may never find a purpose or place in fully realized and rounded outputs. Wilson uses his smart phone for capturing multiple ideas for instrumental parts, unfinished chord sequences or lyrical motifs. Cooper reflects on revisiting Xenomania's accrued and unused "ideas" while on maternity leave and discovering a cache of 52,000 song elements contained in sound files. Such productivity in such instances means that the process of control and editing appears brutal. As Cooper notes of reviewing such a store of ideas: "Literally, you play the first second and we instantly know it, "No, not that one, yes, the next one.' We just know it."

The amount of material Cooper refers to might be exceptional but some writers are adamant that writing something is better than nothing in order to offset the implicit uncertainties of the work one creates. Tom Robinson considers that "If only one song in every ten is any good, unless you write the first nine, you never get to that tenth. Write any old bit of shit! Once it exists, you can change it!" As Guy Chambers relates, this means that not every idea has the same destiny even when realized into whole songs: "I don't know about everyone, but you're going to have some element of wastage, you know, if you write 20 songs, maybe only one has value and that's just how it is." Likewise, Albert Hammond says "I've written, I don't know, 1,000, over 1,000 songs, so yeah, I think the ratio is if you write a lot of songs, you're going to have some hits, there's no doubt, you know, otherwise you're really bad." 
Songs have an existence and meaning qua songs and one of the core aspects of creative risk is the process of making value judgments about when a song is "ready" for instance. Songwriters reveal that songwriting is goal oriented in that its measure lies in realising something finished, a work that feels complete. There is, no doubt, a cynical mode that asks "will this do?" in the context of writing songs to order - as White comments sardonically "Nowadays I'm such a kind of whore, I bash stuff out really fast." Nonetheless, decision-making over one's creativity is tied to a process of quality control, a personalized gatekeeping in which material is revealed to other gatekeepers (publishers, labels, artists etc.). Deciding that a song is finished results in making an assessment of both its very status and success as a song. The latter point relates to a repeated quality in songwriter discourse about how elements fit togetherwhether musically, lyrically or performatively: whether they work as a song, are recognizable, or are convincing. As White says of his collaborative writing, the point can be elaborated with regards to the relationship between feelings of generic production and innovation. Creating something wholly original (or which at least feels original), involves pushing at the boundaries not of songwriting per se but of one's own habitual horizon of possibilities. Such instances might be labeled as the acme of creativity. For instance, Wilson relates that his song "However Long" was something begun in the early 2000s and its development represents a wholly disjointed and non-linear process to its point of "completion": "I have this pile of notecards with song ideas on it and I wrote down the idea on a notecard and then forgot about it for a long time. It really wasn't in my consciousness." In this case, he chanced upon the lyrical idea having forgotten it and was presented with something whose appeal lay in the fact that his own creation had become distant from him, "as though it was someone else's work." This perception gave him a sense of objectivity about his creation, taking him outside of what he realizes is his own formulae or approach.

For professional songwriters, the measure of success is ultimately the salability of a song, which for those who perform their own work may lie in making it available for purchase or as part of a concert set. For those whose work is surveyed here, success is mainly measured in the attractiveness of their songs to other artists, its treatment and interpretation by them and the receptiveness of consumers whose purchase of a song or encounter in a performance also initiates a form of evaluation and appropriation, conditioning the mode of success.

\section{Confirming creativity: being a songwriter}

Ultimately, one means of mitigating the uncertainty of creativity lies in one's very status as a professional songwriter. Chambers notes the obviousness of this in a reflection on the first band that he led: "Once you get signed and you've got records out, you are a professional songwriter." As the aphorism goes: "Nothing succeeds like success" and in the end one can claim to be creative as a result of having one's name on recordings, song sheets, contracts and in contact books. As Skarbek notes: "It's like you're given a sort of badge to wear [...] you're accepted into a certain sort of club. It's an affirmation of what you've been able to do." As Csikszentmihalyi puts it, "Creativity in any form does not come cheap; it requires commitment and perseverance" (253) and the status of songwriter is the ultimate 'output'. As Taylor and Littleton summarize, the meta-product of creativity is the self, its rewards realized in "self-actualization" (4). Having experience, a track record, proving to oneself and others that one is a songwriter, is important for self-assurance and the confidence that 
one has the capabilities required for making songs and indeed for defining what works and what counts. Eg White comments: "I've been writing pop songs for 30 years now, and playing music for another 10 on top of that. I've heard quite a lot." This career represents a considerable personal investment and accretion of experience, expertise and knowledge of what works.

This characteristic seems tautological perhaps, but relates back to perceptions of the exceptionality of this kind of work. After all, how does one become a songwriter and where does one apply for the job? Whatever the availability of courses, qualifications and "how to" books, the concept of a career structure, a path to a sacralized professional status, is not transparent. It is not enough to have written a song, or even some songs: one must continue to write songs in order to inhabit the guise of being a songwriter. To be a songwriter is to assume one is able to continue to deliver songs. The delivery of songs is tied to the expectations and judgments of them by peers, interpreters and consumers who confirm that they are indeed songs and have value, demonstrating their cultural affect and economic effects.

\section{Conclusions}

In this paper, we have argued that songwriting has not been the subject of the kind of extensive attention from researchers that one might expect, considering its elemental place in the value chain of the music industries. This may be due to a fundamental quality of the structure and culture of this area of production that has obfuscated this aspect of the labor of musicians. As Jones has suggested "One of the reasons that songwriting is a difficult occupation to access and interrogate is because the music industry is organized to put us out of touch with prosaic reality (or to put us differently in touch with the everyday)" (246). He cites evidence for this in the ideas that music industry products are escapist rather than utilitarian. This escapist quality is rather nuanced, offering potential hope as much as distraction but does also point to the wider cultural understanding of the music domain and the manner in which it is framed in romantic terms. As we have suggested, explanations for how songwriting happens is often couched in ineffable terms by its producers as much as cultural intermediaries and consumers. Nonetheless, while songwriters might have recourse to such explanations, their discourse reveals a more prosaic reality and insight into everyday creativity and of the production of songs.

Drawing upon accounts of the working practices of songwriters as detailed in the extensive interviews conducted by Sodajerker on Songwriting, has brought us closer to understanding their work as work. Professional songwriting involves effort, skills, knowledge and understanding. Its practitioners have accrued a set of sometimes individualized, sometimes shared approaches to generating songs. As we have argued, the ways in which professional songwriters describe their relationships to creativity, strategy, risk, status and reward is a result of not only a great deal of engagement with the practical process of writing songs, but also of a reflexive understanding of these processes and a recognition that to write a song is a job of work.

We suggest that these insights into the nature of the work of musicians also speak to wider debates about cultural labor and the creativity of the creative industries. One of the problems of attempts to make sense of production in the context of a wider, all-encompassing notion of creative industries is that it has the potential to elide the specificity of a medium and cultural form. Producing music and writing a song is a very particular thing in spite of analogues and comparisons with other forms of creative work, such as poetry or painting for instance. The materiality, form and 
conventions of music merit some reflection for their function and understanding within the field of music as expression and economy.

While we have drawn upon a small sample of interviewees who represent the kind of status and success that many aspire to, there is more to be explored about the songwriter in the wider context of a cultural ecology that would encompass the commercial producer, those who might be publicly supported to write songs, as well as those engaged in "homemade" or amateur production. Across this range we might further understand continuities and indeed distinctions in practice and conceptualisations of the song, its symbolic dimensions, origination and relationship with consumers - imagined or ideal. For anyone who takes seriously the nature of creative work, its routine, banal qualities are well known. Knowing what that routine involves, however, is worthy of closer and systematic attention in order to understand the specificity of this mode of production as work. In so doing, it pushes into the rather sacred domain of creative inspiration and origination that feeds and indeed produces and sustains the music industries. 


\section{Disclosure Statement}

No potential conflict of interest was reported by the author.

\section{Funding}

This research received no specific grant from any funding agency in the public, commercial or not-for-profit sectors.

\section{Notes on Contributors}

Paul Long is Professor of Media and Cultural History in the Birmingham Centre for Media and Cultural Research at Birmingham City University. He is the author of 'Only in the common people': The Aesthetics of Class in Post-War Britain (2008). His writing on popular music includes studies of online heritage projects, memories of live music events, BBC4's Britannia series, Tony Palmer's All You Need is Love as well as the role of student unions in UK popular music culture.

Dr Simon Barber is a Research Fellow in the Birmingham Centre for Media and Cultural Research at Birmingham City University where he pursues his interests in songwriting and the relationships between creative workers and industry. He has published in The European Journal of Cultural Studies, The Radio Journal, The Journal on the Art of Record Production and the Jazz Research Journal among others. He is also the producer and co-presenter of the Sodajerker on Songwriting podcast. 


\section{Bibliography}

Banks, Mark. "Craft Labour And Creative Industries." International Journal of Cultural Policy 16.3 (2010): 305-321. Print.

Banks, Mark, Andy Lovatt, Justin O'Connor and Carlo Raffo. "Risk And Trust In The Cultural Industries." Geoforum 31.4 (2000): 453-464. Print.

Becker, Howard Saul. Art Worlds. 1st ed. Berkeley: University of California Press, 1982. Print.

Becker, Howard S. and Alain Pessin. "A Dialogue On The Ideas Of "World" And "Field"." Social Forum 21.2 (2006): 275-286. Print.

Bennett, Joe. "Collaborative songwriting - the ontology of negotiated creativity in popular music studio practice". Journal on the Art of Record Production 5 (2011): 77-90. Web. 5 Jan. 2017.

Blume, Jason. 6 Steps To Songwriting Success. 1st ed. New York: Billboard Books, 2004. Print.

Bourdieu, Pierre and Randal Johnson. The Field Of Cultural Production. 1st ed. New York: Columbia University Press, 1993. Print.

Burns, Gary. "A Typology Of 'Hooks' In Popular Records". Popular Music 6.01 (1987): 1-20. Print.

Caldwell, John Thornton. Production Culture: Industrial Reflexivity and Critical Practice in Film and Television. Durham, NC: Duke University Press, 2008. Print.

Conor, Bridget. Screenwriting: Creative Labor and Professional Practice. New York: Routledge, 2014. Print.

Coryat, Karl and Nicholas Dobson. The Frustrated Songwriter's Handbook. 1st ed. San Francisco, Calif.: Backbeat, 2006. Print.

Csikszentmihalyi, Mihaly. The Systems Model Of Creativity: The Collected Works of Mihaly Csikszentmihalyi. Dordrecht: Springer, 2014. Print.

de Laat, K. "'Write A Word, Get A Third": Managing Conflict And Rewards In Professional Songwriting Teams". Work and Occupations 42.2 (2015): 225256. Print.

Easlea, Daryl. Everybody Dance. 1st ed. London: Helter Skelter, 2004. Print.

Egan, Sean. The Guys Who Wrote 'Em. 1st ed. London, England: Askill Pub., 2004. Print.

Emerson, Ken. Always Magic In The Air: The Bomp and Brilliance of the Brill Building Era. 1st ed. New York: Penguin Books, 2006. Print.

Fitzgerald, Jon. "When The Brill Building Met Lennon - Mccartney: Continuity And Change In The Early Evolution Of The Mainstream Pop Song". Popular Music and Society 19.1 (1995): 59-77. Print.

George, Nelson. Where Did Our Love Go?. 1st ed. Urbana: University of Illinois Press, 2007. Print.

Gill, Rosalind and Andy Pratt. "In The Social Factory?: Immaterial Labour, Precariousness And Cultural Work." Theory, Culture \& Society 25.7-8 (2008): 130. Print.

Groce, Stephen B. "On The Outside Looking In: Professional Socialization And The Process Of Becoming A Songwriter". Popular Music and Society 15.1 (1991): 33-44. Print.

Harding, Phil. PWL From The Factory Floor. 1st ed. Suffolk: W.B. Publishing, 2009. Print. 
Hass, R. W., R. W. Weisberg, and J. Choi. "Quantitative Case-Studies In Musical Composition: The Development Of Creativity In Popular-Songwriting Teams". Psychology of Music 38.4 (2010): 463-479. Print.

Hesmondhalgh, David. The Cultural Industries. 2nd ed. London: SAGE, 2007. Print. Hesmondhalgh, David and Sarah Baker. Creative Labour: Media Work in Three Cultural Industries. London: Routledge, 2011. Print.

Hirschhorn, Joel. The Complete Idiot's Guide To Songwriting. 1st ed. Indianapolis, IN: Alpha, 2001. Print.

Hochschild, Arlie Russell. "Emotion Work, Feeling Rules, And Social Structure." American Journal of Sociology 85.3 (1979): 551-575. Print.

The Managed Heart. Berkeley: University of California Press, 1983. Print.

Holt, Fabian and Francesco Lapenta. "Introduction: Autonomy And Creative Labour." Journal for Cultural Research 14.3 (2010): 223-229. Print.

Hracs, Brian J and Deborah Leslie. "Aesthetic Labour In Creative Industries: The Case Of Independent Musicians In Toronto, Canada." Area 46.1 (2013): 66-73. Print.

Jasen, David A. Tin Pan Alley: An Encyclopedia of the Golden Age of American Song. 1st ed. Taylor \& Francis, 2003. Print.

Jones, Mike. "The Music Industry As Workplace: An Approach To Analysis". Cultural Work: Understanding The Cultural Industries. Andrew Beck. 1st ed. London: Routledge, 2003. 147-156. Print.

"Writing For Your Supper: Creative Work And The Contexts Of Popular Songwriting". Words And Music. John Williamson. 1st ed. Liverpool: Liverpool University Press, 2004. 219-250. Print.

Kelly, Casey and David Hodge. The Complete Idiot's Guide To The Art Of Songwriting. New York: Alpha, 2011. Print.

Kimpel, Dan. Electrify My Soul. Boston: Thomson Course Technology, 2008. Print.

Littleton, Karen, Stephanie Taylor, and Anneli Eteläpelto. "Special Issue Introduction: Creativity And Creative Work In Contemporary Working Contexts." Vocations and Learning 5.1 (2011): 1-4. Print.

Long, Paul and Simon Barber. "Voicing Passion: The Emotional Economy Of Songwriting." European Journal of Cultural Studies 18.2 (2014): 142-157. Print.

Mayer, Vicki, Miranda J. Banks, and John Thornton Caldwell, eds. Production Studies. New York: Routledge, 2009. Print.

McIntyre, Phillip. "Creativity And Cultural Production: A Study Of Contemporary Western Popular Music Songwriting". Creativity Research Journal 20.1 (2008): 40-52. Print.

McRobbie, Angela. British Fashion Design: Rag Trade or Image Industry? London: Routledge, 1998. Print.

Menger, Pierre-Michel. The Economics Of Creativity. Cambridge, MA: Harvard University Press, 2014. Print.

Murray, Catherine and Mirjam Gollmitzer. "Escaping The Precarity Trap: A Call For Creative Labour Policy." International Journal of Cultural Policy 18.4 (2012): 419-438. Print.

Negus, Keith and Michael Pickering. Creativity, Communication And Cultural Value. London: Sage Publications, 2004. Print.

Oakley, Kate and Justin O'Connor. The Routledge Companion To The Cultural Industries. 1st ed. New York: Routledge, 2015. Print.

Pang, Laikwan. "The Labor Factor In The Creative Economy: A Marxist Reading." Social Text 27.2 (2009): 55-76. Print. 
Pattison, Pat. Song-Writing Without Boundaries. Cincinnati, Ohio: Writer's Digest, 2011. Print.

Rachel, Daniel. Isle Of Noises: Conversations With Great British Songwriters. 1st ed. London: Picador, 2013. Print.

Sawyer, R. Keith. Group Creativity: Music, Theatre, Collaboration. Mahwah, NJ: Lawrence Erlbaum Associates, 2003. Print.

Taylor, Stephanie and Karen Littleton. Contemporary Identities Of Creativity And Creative Work. Farnham: Ashgate Publishing Ltd, 2012. Print.

Toynbee, Jason. Making Popular Music. 1st ed. London: Arnold, 2000. Print.

Tschmuck, Peter. Creativity And Innovation In The Music Industry. 1st ed. Dordrecht: Springer, 2012. Print.

Turner, Steve. A Hard Day's Write: The Stories Behind Every Beatles Song. New York: Harper, 2005. Print.

Weisberg, Robert W. Creativity: Understanding Innovation in Problem Solving, Science, Invention, and the Arts. Hoboken, NJ: John Wiley \& Sons, 2006. Print.

Wilson, Dan. "However Long (Ballroom Demo)". Dan Wilson. 2013. Web. 5 Jan. 2017.

Zollo, Paul. Songwriters On Songwriting. 2nd ed. Cambridge, MA: Da Capo, 2003. Print.

\section{Notes}

${ }^{1}$ All quoted interviews are sourced from Sodajerker on Songwriting, an audio podcast licensed via Creative Commons, which can be found online here:

http://www.sodajerker.com/podcast. 